\title{
Investment Risk Evaluation for Demand Side Management: Improved Bayesian Model
}

\author{
Changxin Yin ${ }^{1}$ \&Ming Zeng ${ }^{2} \&$ Xuefeng $\mathrm{Ma}^{3}$ \& Lu Yin ${ }^{3}$ \& Yang Lv ${ }^{3}$ \\ $\&$ Bin Shu ${ }^{3} \&$ Chunxue $\mathrm{Li}^{4}$ \\ ${ }^{1}$ State Grid Beijing Electric Power Company \\ ${ }^{2}$ School of Economic and Management, North China Electric Power University \\ ${ }^{3}$ Beijing Electric Power Economic Research Institute \\ ${ }^{4}$ School of Economic and Management, North China Electric Power University
}

KEYWORD: DSM; investment risk; Bayesian risk investment evaluation model; Entropy Weight method; Normalization method.

ABSTRACT: The vigorous promotion of DSM is of great significance in improving energy conservation and power system reliability. At present, DSM technology of China has been developed, meanwhile, related projects will be carried out extensively. Therefore, investment risk evaluation for DSM projects of power enterprises is of significant urgency. To begin with we will provide investment risk evaluation system for DSM projects based on characteristics of power utilization in China. Secondly, the improved Bayesian risk investment evaluation model will be established. Compared with traditional Bayesian model, Entropy Weight method will be used to calculate the weight of every index. At the same time, Normalization method has been introduced to normalize the value of indices. Last but not least, analysis of examples is preceded to prove the practicality of the model in this paper and provide a reference for the DSM projects in power enterprises.

\section{Introduction}

DSM is able to reduce peak load and ease the tension between power supply and demand. Besides, the cost of electricity supply and utilization will also be reduced, so that DSM technology has been widely used around the world during the recent years [1], [2]. With the continuous progress of the reform, China's power industry and electricity market design is also moving away from the previous supply side management to the bidirectional management with both supply side management and demand side management. At the same time, energy planning in China has developed from supply side planning towards integrated resource planning[3], [4]. Meanwhile, management of China's electricity utilization is gradually leading towards the demand side management direction which acquires more characteristics of market [5]. As a result, a large number of demand side management research and development projects as well as equipment renovation projects have been put into implementation. Therefore, the research of investment risk of DSM projects is of great importance in promoting the safe and sustainable development of electric power system in China. This paper has introduced the Bayesian evaluation model to evaluate the risk during the investment period of DSM projects. In order to improve the accuracy of this model, Entropy Weight method and Normalization method will also be introduced as well. Through the example analysis, the rationality of improved model has been proved.

\section{Evaluation system}

According to the characteristics of power utilization in China, this paper has separated the benefits and costs of DSM projects into four categories: social benefits, power users, power grid enterprises and power generation enterprises. Based on the four categories, the investment risk evaluation system for DSM projects has been established as shown in Table1. 
Table 1. Investment risk evaluation system for DSM projects

\begin{tabular}{|c|c|c|}
\hline Categories & $\begin{array}{l}\text { Code of } \\
\text { Indices }\end{array}$ & Indices \\
\hline $\begin{array}{l}\text { Social } \\
\text { benefits }\end{array}$ & $I_{1}$ & $\begin{array}{l}\text { Reduction of gas emis- } \\
\text { sion }\end{array}$ \\
\hline \multirow[b]{2}{*}{$\begin{array}{l}\text { Power us- } \\
\text { ers }\end{array}$} & $I_{2}$ & $\begin{array}{l}\text { Reduction of electricity } \\
\text { charge }\end{array}$ \\
\hline & $I_{3}$ & $\begin{array}{l}\text { Reduction of the } \\
\text { cost of restricting } \\
\text { power use }\end{array}$ \\
\hline \multirow{3}{*}{$\begin{array}{l}\text { Power } \\
\text { grid enter- } \\
\text { prises }\end{array}$} & $I_{4}$ & Increase in load rate \\
\hline & $I_{5}$ & $\begin{array}{l}\text { Reduction of in- } \\
\text { vestment costs of } \\
\text { supply side }\end{array}$ \\
\hline & $I_{6}$ & $\begin{array}{l}\text { Reduction of operation } \\
\text { and maintenance costs }\end{array}$ \\
\hline \multirow{3}{*}{$\begin{array}{l}\text { Power } \\
\text { generation } \\
\text { enterprises }\end{array}$} & $I_{7}$ & $\begin{array}{l}\text { Increase in the rate of } \\
\text { generation equipment uti- }\end{array}$ \\
\hline & $I_{8}$ & $\begin{array}{l}\text { The benefits of } \\
\text { postponed power } \\
\text { supply construc- }\end{array}$ \\
\hline & $I_{9}$ & Reduction of fuel costs \\
\hline
\end{tabular}

\section{Improved Bayesian model}

\section{Standardization of indices through Normalization method}

In the decision matrix $X=\left(x_{i j}\right)_{\text {non }}$, the number of decision indices is $n$, meanwhile, the number of schemes is $m$. In this model, all ${ }^{n}$ ndices are positive indices, besides, the value of indices are greater than zero. At the same time, the relationship between indices should be reflected in this model, therefore Normalization method will be introduced to standardize value of the indices [12]. So the standardization process is as follows.

$$
y_{i j}=\frac{x_{i j}}{\sum_{i=1}^{m} x_{i j}} \quad(1 \leq i \leq m, 1 \leq j \leq n)
$$

As a result, $Y=\left(y_{i j}\right)_{m \times n}$ is the index matrix after standardization.

\section{Weight determination through Entropy Weight method}

This paper introduces entropy method to calculate the weight of each indicator. We take the input variables as examples, and the steps of calculation process are as follows.

(1) $z_{i k}$ stands for the input value of input variable $\mathrm{i}$ from decision-making unit $\mathrm{k}$, and the matrix of raw index data $Z=\left(z_{i k}\right)_{m \times t}$ will be generated[13].

(2) The proportion $p_{i j}$, which stands for the proportion of input value $\mathrm{j}$, is able be calculated through equation (2), $m$ represents the number of indicators.

$p_{i j}=z_{i j} / \sum_{i=1}^{m} z_{i j}$

(3) $c_{i}$ stands for the entropy of indicator i, which can be calculated through equation(3), among those, $h=1 / \ln m[14]$.

$c_{i}=-h \sum_{i=1}^{m} p_{i j} \cdot \ln p_{i j}$

(4) The value of $w_{i}$, which represents the entropy weight of indicator i, can be calculated through the equation (4). 
$w_{i}=\left(1-c_{i}\right) / \sum_{i=1}^{m}\left(1-c_{i}\right)$

\section{Bayesian risk investment evaluation model}

The Bayesian risk investment evaluation model will be able to be established based on the investment risk evaluation system for DSM projects.

In decision-making space $D=\left\{d_{1}, d_{2}, \ldots, d_{n}\right\}, d_{x}$ represents decision scheme, $D$ is the state space. Among those, $\sigma_{1}, \sigma_{2}$ and $\sigma_{3}$ separately reflect that the situation of the market is poor, general and preferable[7], [8]. Therefore, $P\left(\sigma_{1}\right), P\left(\sigma_{2}\right), P\left(\sigma_{3}\right)$ demonstrates the probability of $\sigma_{1}, \sigma_{2}$ and $\sigma_{3}$. According to the authoritative analysis report, this paper sets $P\left(\sigma_{1}\right)=0.2, P\left(\sigma_{2}\right)=0.4$, $P\left(\sigma_{3}\right)=0.4$. Obviously, there is a risk in this prediction, so the risk factors should be added into the prediction of market situation. In this model, $z_{1}, z_{2}$ and $z_{3}$ means the prediction accuracy is poor, general, preferable[9], [10].

Besides, weight vector is $U=\left(u_{1}, u_{2} \ldots, u_{14}\right), u_{1}, u_{2} \ldots, u_{14}$ represents the weight of every index, $I_{1}, I_{2} \ldots, I_{14}$. Therefore the benefit function can be obtained, as shown in Equation (5) [11].

$V=u_{1} I_{1}+u_{2} I_{2}+\mathrm{L}+u_{14} I_{14}$

This paper will analyze investment risk of DSM projects in power enterprises. The risk decision table is shown in Table 2.

Table 2 Risk decision table

\begin{tabular}{|c|c|c|c|}
\hline \multirow[t]{2}{*}{ Market } & $\sigma_{1}$ & $\sigma_{2}$ & $\sigma_{3}$ \\
\hline & $P\left(\sigma_{1}\right)$ & $P\left(\sigma_{2}\right)$ & $P\left(\sigma_{3}\right)$ \\
\hline \multicolumn{4}{|l|}{ Scheme } \\
\hline $\begin{array}{l}\text { Scheme } 1 \\
\text { Scheme } 2 \\
\text { Scheme } 3\end{array}$ & $\begin{array}{l}a_{11} \\
a_{21} \\
a_{31}\end{array}$ & $\begin{array}{l}a_{12} \\
a_{32} \\
a_{32}\end{array}$ & $\begin{array}{l}a_{13} \\
a_{33} \\
a_{33} \\
\end{array}$ \\
\hline
\end{tabular}

Benefit of every scheme is shown in Equation (6).

$$
E\left(V_{i}\right)=P\left(\sigma_{1}\right) a_{i 1}+P\left(\sigma_{2}\right) a_{i 2}+P\left(\sigma_{3}\right) a_{i 3}
$$

The goal of decision-making process is to achieve maximum benefit. Therefore the basis of selection is demonstrated in Equation (7).

$$
E\left(V_{i}\right)_{\max }=\max E\left(V_{i}\right)(i \in[1, n])
$$

Besides, the risk factor of prediction will be introduced into the modeling, the table of relevance between the prediction of market situation and the prediction accuracy are shown in Table 3.

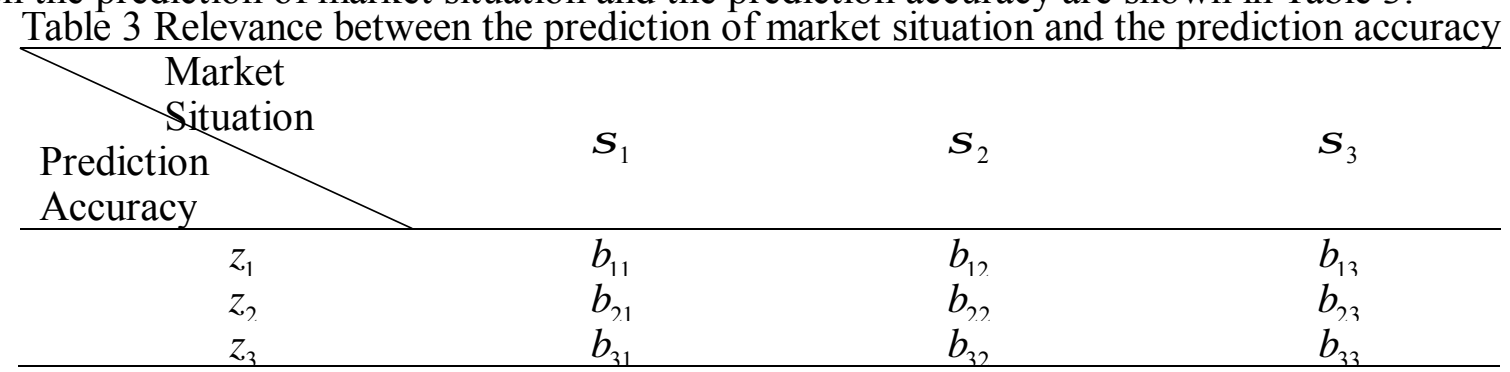

The Bayesian formula can be used to calculate the investment efficiency under the consideration of risk factors. Besides, Bayesian formula is shown in Equation (8).

$$
P\left(\sigma_{i} \mid z_{j}\right)=\frac{P\left(\sigma_{i} z_{j}\right)}{P\left(z_{j}\right)}=\frac{P\left(\sigma_{i}\right) P\left(z_{j} \mid \sigma_{i}\right)}{\sum_{k=1}^{5} P\left(\sigma_{k}\right) P\left(z_{j} \mid \sigma_{k}\right)}
$$




\section{Practical application of improved Bayesian model}

The data in this paper was derived from a series of projects which were conducted by a provincial power grid enterprise in China. After the implementation of projects, analysis and prediction of these projects has been preceded, the data of schemes was collected in table 4 .

Table 4. Data of schemes

\begin{tabular}{|c|c|c|c|c|}
\hline $\begin{array}{l}\text { The } \\
\text { code of } \\
\text { indices }\end{array}$ & Schemes & $\begin{array}{l}\text { Market sit- } \\
\text { uation } \sigma_{1}\end{array}$ & $\begin{array}{l}\text { Market sit- } \\
\text { uation } \sigma_{2}\end{array}$ & $\begin{array}{l}\text { Market sit- } \\
\text { uation } \sigma_{3}\end{array}$ \\
\hline$I_{1}($ ten & A & 412.04 & 453.19 & 488.20 \\
\hline thousand & B & 422.17 & 465.58 & 490.54 \\
\hline tons) & $\mathrm{C}$ & 487.09 & 517.08 & 520.18 \\
\hline$I_{2}($ ten & A & 411.45 & 464.51 & 470.52 \\
\hline thousand & B & 590.11 & 649.23 & 689.10 \\
\hline Yuan) & $\mathrm{C}$ & 402.16 & 432.66 & 440.77 \\
\hline$I_{2}($ ten & $\mathrm{A}$ & 799.14 & 821.33 & 833.78 \\
\hline thousand & B & 968.23 & 1069.25 & 1120.30 \\
\hline Yuan) & $\mathrm{C}$ & 902.28 & 986.48 & 1090.52 \\
\hline \multirow{3}{*}{$I_{4}(\%)$} & A & 0.0013 & 0.0113 & 0.0178 \\
\hline & B & 0.0614 & 0.0996 & 0.1296 \\
\hline & $\mathrm{C}$ & 0.0725 & 0.0945 & 0.1400 \\
\hline$I_{5}($ ten & A & 418.12 & 456.32 & 473.24 \\
\hline thousand & B & 205.58 & 223.46 & 250.02 \\
\hline Yuan) & $\mathrm{C}$ & 411.23 & 455.26 & 467.93 \\
\hline$I_{6}($ ten & A & 101.55 & 135.85 & 190.35 \\
\hline thousand & B & 103.17 & 128.98 & 150.01 \\
\hline Yuan) & $\mathrm{C}$ & 111.44 & 135.13 & 144.29 \\
\hline \multirow{3}{*}{$I_{7}(\%)$} & A & 12.57 & 17.66 & 18.16 \\
\hline & B & 13.19 & 15.89 & 18.39 \\
\hline & C & 12.26 & 16.36 & 18.25 \\
\hline \multirow{3}{*}{$I_{8}(\mathrm{kWh})$} & $\mathrm{A}$ & 122.36 & 131.45 & 158.79 \\
\hline & B & 101.19 & 124.88 & 149.71 \\
\hline & C & 132.07 & 143.67 & 161.61 \\
\hline$I_{0}($ ten & $\mathrm{A}$ & 566.79 & 590.32 & 602.65 \\
\hline thousand & B & 603.18 & 655.39 & 672.90 \\
\hline Yuan) & C & 629.99 & 674.23 & 690.77 \\
\hline
\end{tabular}

The standardization of the value of data will be conducted through Normalization method. The results are shown in the following tables.

Table 5. The value of $I_{1}$ after standardization

\begin{tabular}{lllll}
\hline $\begin{array}{l}\text { The code of } \\
\text { index }\end{array}$ & Scheme & Market situation & Market situation & Market situation \\
$\sigma_{3}$ & $\sigma_{1}$ & 0.316 & 0.326 \\
$I_{1}$ & $\mathrm{~A}$ & 0.311 & 0.324 & 0.327 \\
& $\mathrm{~B}$ & 0.320 & 0.360 & 0.347 \\
\hline
\end{tabular}

Table 6 . The value of $I_{2}$ after standardization

\begin{tabular}{lllll}
\hline $\begin{array}{l}\text { The code of } \\
\text { index }\end{array}$ & Scheme & $\begin{array}{l}\text { Market situation } \\
\sigma_{1}\end{array}$ & $\begin{array}{l}\text { Market situation } \\
\sigma_{2}\end{array}$ & $\begin{array}{l}\text { Market situation } \\
\sigma_{3}\end{array}$ \\
\hline \multirow{2}{*}{$I_{2}$} & $\mathrm{~A}$ & 0.294 & 0.300 & 0.294 \\
& $\mathrm{~B}$ & 0.420 & 0.420 & 0.431 \\
\hline
\end{tabular}

Table 7. The value of $I_{3}$ after standardization

\begin{tabular}{lllll}
\hline $\begin{array}{l}\text { The code of } \\
\text { index }\end{array}$ & Scheme & $\begin{array}{l}\text { Market situation } \\
\sigma_{1}\end{array}$ & $\begin{array}{l}\text { Market situation } \\
\sigma_{2}\end{array}$ & $\begin{array}{l}\text { Market situation } \\
\sigma_{3}\end{array}$ \\
\hline \multirow{2}{*}{$I_{3}$} & A & 0.299 & 0.285 & 0.274 \\
& B & 0.363 & 0.372 & 0.368 \\
\hline
\end{tabular}


Table 8 . The value of $I_{4}$ after standardization

\begin{tabular}{lllll}
\hline $\begin{array}{l}\text { The code of } \\
\text { index }\end{array}$ & Scheme & $\begin{array}{l}\text { Market situation } \\
\sigma_{1}\end{array}$ & $\begin{array}{l}\text { Market situation } \\
\sigma_{2}\end{array}$ & $\begin{array}{l}\text { Market situation } \\
\sigma_{3}\end{array}$ \\
\hline \multirow{2}{*}{$I_{4}$} & $\mathrm{~A}$ & 0.010 & 0.055 & 0.062 \\
& $\mathrm{~B}$ & 0.454 & 0.485 & 0.451 \\
\hline
\end{tabular}

Table 9. The value of $I_{5}$ after standardization

\begin{tabular}{lllll}
\hline $\begin{array}{l}\text { The code of } \\
\text { index }\end{array}$ & Scheme & $\begin{array}{l}\text { Market situation } \\
\sigma_{1}\end{array}$ & $\begin{array}{l}\text { Market situation } \\
\sigma_{2}\end{array}$ & $\begin{array}{l}\text { Market situation } \\
\sigma_{3}\end{array}$ \\
\hline \multirow{2}{*}{$I_{5}$} & A & 0.404 & 0.402 & 0.397 \\
& B & 0.199 & 0.197 & 0.210 \\
& C & 0.397 & 0.401 & 0.393 \\
\hline
\end{tabular}

Table 10. The value of $I_{6}$ after standardization

\begin{tabular}{lllll}
\hline $\begin{array}{l}\text { The code of } \\
\text { index }\end{array}$ & Scheme & Market situation & Market situation & Market situation \\
$\sigma^{*}$ & $\sigma_{1}$ & $\sigma_{3}$ & 0.392 \\
$I_{6}$ & A & 0.322 & 0.340 & 0.310 \\
& B & 0.326 & 0.322 & 0.298 \\
\hline
\end{tabular}

Table 11. The value of $I_{7}$ after standardization

\begin{tabular}{lllll}
\hline $\begin{array}{l}\text { The code of } \\
\text { index }\end{array}$ & \multirow{2}{*}{ Scheme } & $\begin{array}{l}\text { Market situation } \\
\sigma_{1}\end{array}$ & $\begin{array}{l}\text { Market situation } \\
\sigma_{2}\end{array}$ & $\begin{array}{l}\text { Market situation } \\
\sigma_{3}\end{array}$ \\
\hline \multirow{2}{*}{$I_{7}$} & $\mathrm{~A}$ & 0.331 & 0.354 & 0.331 \\
& $\mathrm{~B}$ & 0.347 & 0.318 & 0.336 \\
\hline
\end{tabular}

Table 12. The value of $I_{8}$ after standardization

\begin{tabular}{lllll}
\hline $\begin{array}{l}\text { The code of } \\
\text { index }\end{array}$ & Scheme & $\begin{array}{l}\text { Market situation } \\
\sigma_{1}\end{array}$ & $\begin{array}{l}\text { Market situation } \\
\sigma_{2}\end{array}$ & $\begin{array}{l}\text { Market situation } \\
\sigma_{3}\end{array}$ \\
\hline \multirow{2}{*}{$I_{8}$} & A & 0.344 & 0.329 & 0.338 \\
& B & 0.285 & 0.312 & 0.318 \\
\hline
\end{tabular}

Table 13. The value of $I_{9}$ after standardization

\begin{tabular}{lllll}
\hline $\begin{array}{l}\text { The code of } \\
\text { index }\end{array}$ & Scheme & Market situation & Market situation & Market situation \\
$\sigma_{3}$ & $\sigma_{1}$ & $\sigma_{3}$ & 0.306 \\
$I_{9}$ & A & 0.315 & 0.307 & 0.343 \\
& B & 0.335 & 0.341 & 0.351 \\
\hline
\end{tabular}

Weight vector of indices is able to be calculated through the Entropy Weight method. The result is shown as follows.

$U=(0.1437,0.1508,0.2721,0.0856$,

$0.1132,0.0414,0.0049,0.0422,0.1461)$

Based on the model established in the former section, the benefit of all schemes is shown in table 14 . 
Table 14. The results of benefit calculations

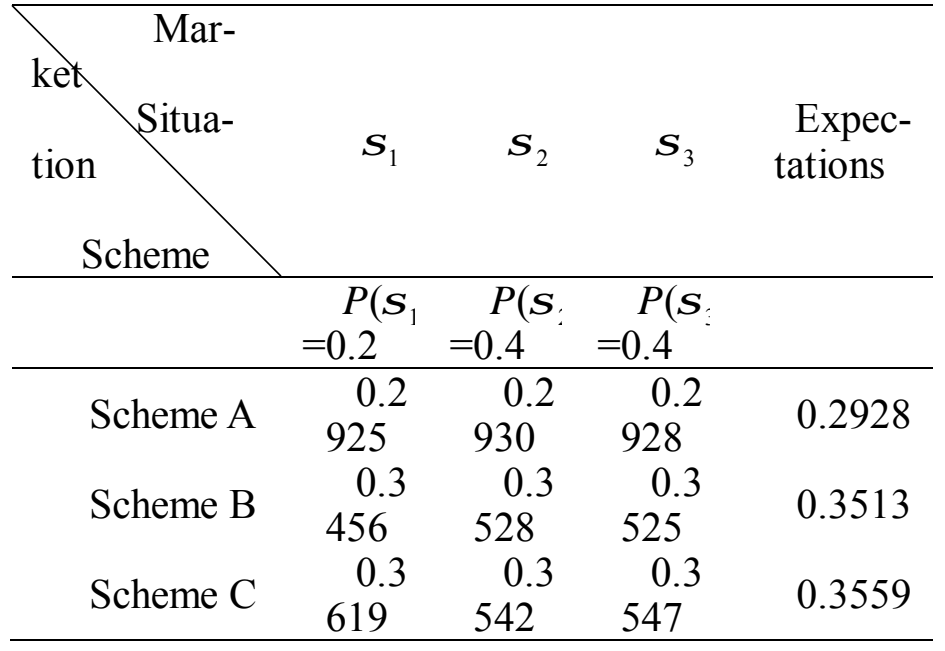

Through the statistical analysis of the data and the collection of comprehensive information from all aspects, the relationship between prediction accuracy and market situation is shown in table 15 .

Table 15. Relationship between prediction accuracy and market situation

\begin{tabular}{cccc}
$\begin{array}{c}\text { Market } \\
\text { Situation }\end{array}$ & $\sigma_{1}$ & $\sigma_{3}$ \\
\hline$z_{1}$ & & & \\
\hline$z_{2}$ & 0.78 & 0.12 & 0.10 \\
$z_{3}$ & 0.12 & 0.81 & 0.07 \\
\hline
\end{tabular}

The prediction accuracy will be introduced into the Bayesian model, so the investment risk-benefit values can be calculated, the results are shown in Table 16.

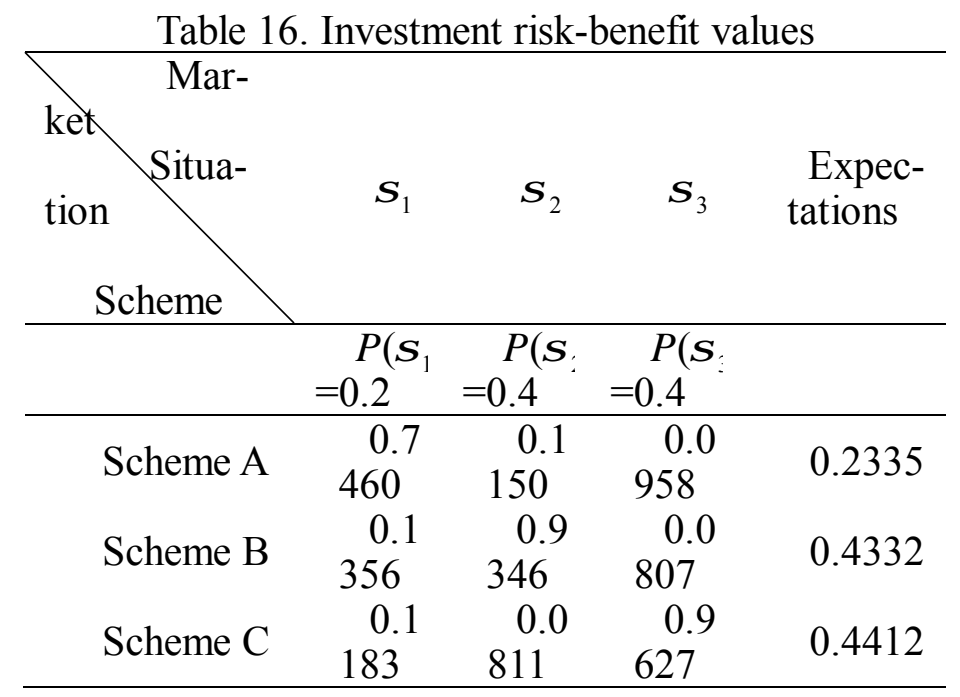

According to the results, the scheme $\mathrm{C}$ has the highest expectations. Therefore the scheme $\mathrm{C}$ has higher investment incomes and lower risk, so the scheme $\mathrm{C}$ is a better option. This result is in accordance with the practical implementation of the projects.

\section{Conclusions}

The promotion of DSM helps to meet the growing demand for electricity in all aspects and improve the economic efficiency of power system operation. At the same time, the resource consumption will be reduced. Meanwhile, the goal of energy conservation and emission reduction will be achieved. 
According to the situation that DSM projects have gradually developed during the recent years, research about investment risk evaluation mechanism for DSM projects is of great significance.

In this paper, we improved the Bayesian model to analyze the investment risk of DSM projects of power grid enterprises. As proved in this paper, the introduction of Entropy Weight method and Normalization method helps to calculate the weight of indices and standardize the value of indices. As shown in the analysis, the improved Bayesian model is able to evaluate the investment risk of DSM projects accurately. In conclusion, the model and the theory in this paper have great importance in realizing the optimization of resource distribution in demand side.

\section{References}

[1] Lin Bo-qiang, Wu Ya, Zhang Li. Electricity saving potential of the power generation industry in China. Energy. 2012; 40(1): 307-316.

[2] Yu Yong-zhen. How to fit demand side management (DSM) into current Chinese electricity system reform?. Energy Economics. 2012; 34(2): 549-557.

[3] Zhao Xiao-li, Li Na, Ma Chun-bo. Residential energy consumption in urban China: A decomposition analysis. Energy Policy. 2012; 41: 644-653.

[4] Hermagasantos Zein, Yusra Sabri, Ali Mashar. Implementation of Electricity Competition Framework with Economic Dispatch Direct Method. TELKOMNIKA. 2012; 10(4): 625-632.

[5] Yu Yong-zhen. Policy redesign for solving the financial bottleneck in demand side management(DSM) in China. Energy Policy. 2010; 38(10): 6101-6110.

[6] Zeng Ming, Xue Song, Ma Ming-juan et al. Historical review of demand side management in China: Management content,operation mode,results assessment and relative incentives. Renewable and Sustainable Energy Reviews. 2013; 25: 470-482.

[7] Abhijit Patil, Deng Zhi-Qiang. Bayesian approach to estimating margin of safety for total maximum daily load development. Journal of Environmental Management. 2012; 92(3): 910-918.

[8] Changwon Yoo. The Bayesian method for causal discovery of latent-variable models from a mixture of experimental and observational data. Computational Statistics and Data Analysis. 2012; 56(7): 2183-2205.

[9] Andrés R.Masegosa, Serafín Moral. New skeleton-based approaches for Bayesian structure learning of Bayesian networks. Applied Soft Computing. 2013; 13(2): 1110-1120.

[10]Xin Li, Ting Li. E-commerce System Security Assessment based on Bayesian Network Algorithm Research. TELKOMNIKA. 2013; 11(1): 338-344.

[11]Li Dan, Wang Jian-hua, Chen Di-fang. E-Bayesian Estimation and Hierarchical Bayesian Estimation for Estate Probability in Engineering. Systems Engineering Procedia. 2012; 5: 349-354.

[12]Dong Ji-yang, Kian-Kai Cheng, Xu Jingjing et al. Group aggregating normalization method for the preprocessing of NMR-based metabolomic data. Chemometrics and Intelligent Laboratory Systems. 2011; 108(2): 123-132.

[13] Guo Ye-cai, Gong Xiu-li, Chen Qu. Quadratic Inverse Function Tsallis Entropy Multimodulus Blind Equalization Algorithm. TELKOMNIKA. 2013; 11(4): 1973-1982.

[14]Ke Zhao. The Research of Gray Algorithm and Information Entropy in Route Planning Optimization. TELKOMNIKA. 2012; 10(8): 2027-2033. 